Soluble Polystyrene-Based Sulfoxide Leave this area blank for abstract info. Reagents for Swern Oxidation Reactions

Matthew Kwok Wai Choi and Patrick H. Toy*

Department of Chemistry, The University of Hong Kong, Pokfulam Road, Hong Kong, P. R. of China.
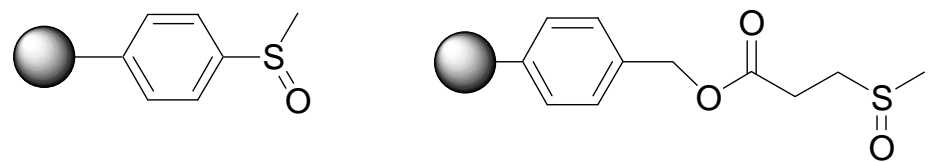


\title{
Soluble Polystyrene-Based Sulfoxide Reagents for Swern Oxidation Reactions
}

\author{
Matthew Kwok Wai Choi and Patrick H. Toy ${ }^{*}$ \\ Department of Chemistry, The University of Hong Kong, Pokfulam Road, Hong Kong, P. R. of China.
}

\begin{abstract}
Two new soluble polystyrene-based sulfoxide reagents are introduced. These polymeric reagents are used in Swern oxidation reactions where the resulting sulfide polymers are easily separated from the product by simple precipitation and filtration. The recovered reduced polymer reagents can be recycled by oxidation with tert-butyl hydroperoxide in the presence of acid. Attempts to use these reagents in a multi-polymer Swern oxidation reaction system were unsuccessful. (c) 2008 Elsevier Science. All rights reserved
\end{abstract}

\section{Introduction}

The oxidation of alcohols to carbonyl compounds is one of the fundamental classes of reactions in organic chemistry. Methyl sulfoxide-based oxidation is one such reaction and it is among the most widely used methods for oxidizing primary and secondary alcohols to aldehydes and ketones, respectively. ${ }^{1}$ The broad range of oxidation applications in which this reaction has been applied has meant that it is continuously being refined and improved. ${ }^{2}$ In these reactions, methyl sulfoxde is activated and reacts with an alcohol to form a dimethylalkoxysulfonium salt. Upon treatment with a base, the salt is deprotonated and affords the desired carbonyl compound and methyl sulfide. A variety of electrophilic reagents have been used to activate methyl sulfoxide including acetic anhydride, ${ }^{3} p$ toluenesulfonyl chloride, ${ }^{4}$ phosgene, ${ }^{5}$ and cyanuric chloride. ${ }^{6}$ Among the various activators, oxalyl chloride has established itself as the most broadly used reagent for methyl sulfoxide-based alcohol oxidation in what is known as the Swern oxidation reaction. ${ }^{7}$ However, one drawback of all of these reactions is that they produce the pungent smelling and highly volatile byproduct methyl sulfide and thus the modification of the Swern oxidation reaction to eliminate the formation of this toxic substance has been a popular research topic.

The use of insoluble polymer supports to deliver reagents and remove their byproducts is now commonplace., Vederas et al. have applied this methodology to the Swern oxidation reaction by attaching 6-(methylsulfinyl)hexanoic acid to commercial chloromethyl polystyrene beads (Merrifield resin) to prepare an insoluble methyl sulfoxide equivalent. $^{10,11}$ They observed that this reagent afforded high yields of oxidation products but that when the recovered polymer was oxidized by sodium periodate, the effectiveness of the recycled reagent was reduced. Therefore, they then attached 6-(methylsulfinyl)hexanoic acid to the soluble polymer poly(ethylene glycol). ${ }^{12}$ This polymer supported reagent showed no loss of activity upon recycling. Recently, Crich et al. have reported a fluorous Swern oxidation reaction that uses tridecafluorooctylmethyl sulfoxide, which can be recovered and reused via a simple continuous fluorous extraction procedure followed by reoxidation with hydrogen peroxide. ${ }^{13}$ Finally, Node et al. have also introduced a new odorless protocol for the Swern oxidation that uses dodecyl methyl sulfoxide in place of methyl sulfoxide. ${ }^{14}$

Soluble polymers are alternative supports to insoluble resins for synthesis and reagent delivery and are becoming widely used. $^{15}$ One such polymer, non-crosslinked polystyrene (NCPS) has been used in a range of application that include as a support for the synthesis of peptides ${ }^{16}$ and prostaglandins $^{17}$ and for the delivery of $\operatorname{tin}^{18}$ and phosphorous $^{19}$ reagents. It is easily prepared with a wide variety of functional groups by the radical copolymerization of styrene with a functionalized styrene. ${ }^{20}$ NCPS has even been used as a support for the Dess-Martin periodinane oxidation reagent. ${ }^{21,22}$

We have previously reported the use of NCPS to deliver triethylamine equivalents in the REM resin-based solid-

\footnotetext{
* Corresponding author. Tel.: +852-2859-2167; fax: +825-2857-1586; e-mail: phtoy@hkucc.hku.hk.
} 
phase synthesis of tertiary amines. ${ }^{23}$ This report is noteworthy in that it is one of the few published examples of a multi-polymer reaction system where a soluble polymer is used to deliver a reagent or substrate to an insoluble polymer. $^{24,25}$ Therefore, we sought to extend this methodology by using NCPS to deliver the base to methyl sulfoxide derivatized NCPS in a multi-polymer Swern oxidation reaction system.

\section{Results and discussion}

In order to develop a multi-polymer Swern oxidation reaction system, we prepared a soluble analogue of Crosby's thioanisole reagent ${ }^{11}$ as outlined in Scheme 1. Monomer 1a was prepared according to the literature procedure ${ }^{26}$ and was co-polymerized with styrene to afford polymer $\mathbf{2 a}$.

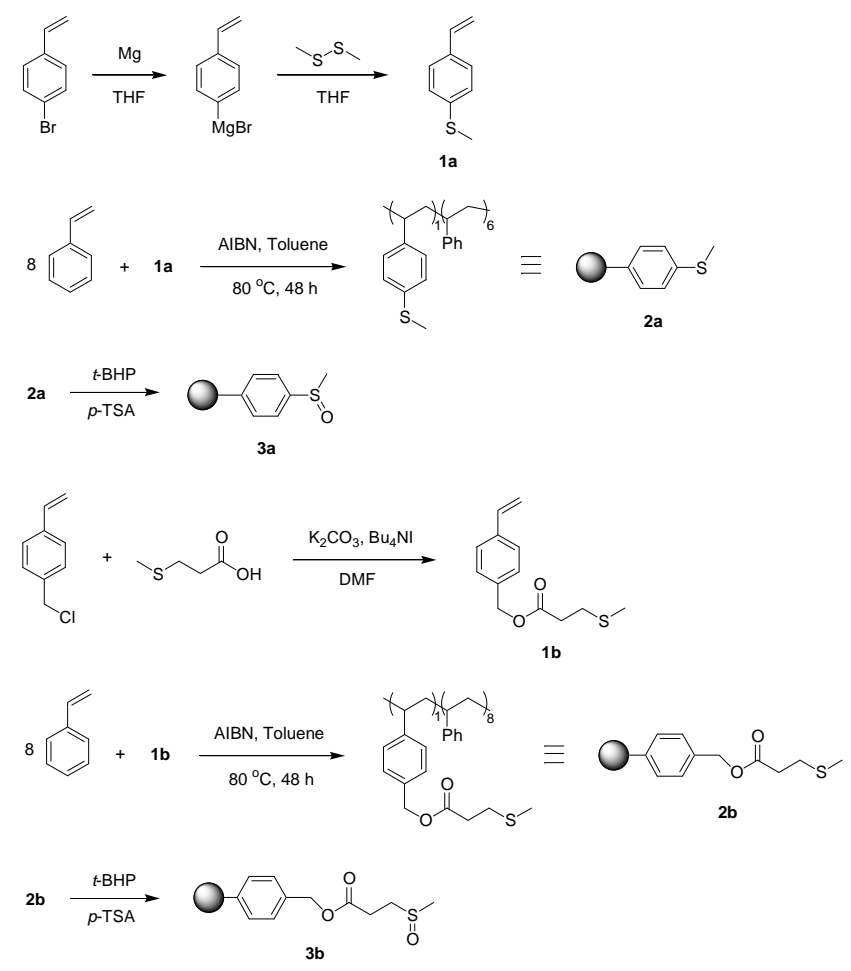

Scheme 1. Synthesis of sulfoxide polymers $\mathbf{3 a}$ and $\mathbf{3 b .}$

The sulfide moieties of 2a were oxidized using t-butyl hydroperoxide $(t-\mathrm{BHP})^{27}$ to afford sulfoxide polymer $3 \mathbf{a}$. The loading level of 3a was determined by elemental analysis (S content) to be $1.25 \mathrm{mmol} / \mathrm{g}$. This was in agreement to the loading of $\mathbf{2 a}$ determined by ${ }^{1} \mathrm{H}$ NMR analysis. The fact that the ratio of monomer incorporation (styrene:1a) differs from the ratio of monomer input indicates that 1a more readily participates in the polymerization process (see experimental). The use of $\mathbf{3 a}$ in the Swern oxidation of secondary alcohols was examined and these results are listed in Table 1 . The reactions were carried out using oxalyl chloride activation and with triethylamine as the base. After addition of the base, the mixture was partially concentrated in vacuo and poured into methanol to precipitate the mixture of 2a and 3a. These polymers were filtered off and the resulting methanol solution was again concentrated in vacuo. The resulting product was then filtered through a plug of silica gel to afford the product ketone that was essentially pure as determined by ${ }^{1} \mathrm{H}$ NMR analysis. Having developed a protocol for the facile isolation of pure oxidation products using 3a, we next examined replacing triethylamine with the polymer $\mathbf{4}^{23}$ (Figure 1). Unfortunately, attempts to use 4 for the deprotonation step in a multi-polymer oxidation system failed.

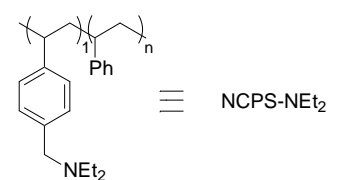

4

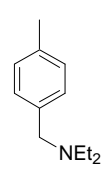

Figure 1.

The failure of 3a to work in a multi-polymer system led us to prepare polymer $\mathbf{3 b}$ (Scheme 1), in which the sulfoxide moieties are further removed from the polymer backbone than they are in 3a, to examine if steric effects between the two polymer backbones caused the failure of $\mathbf{4}$. Monomer 1b was prepared from 4-vinylbenzyl chloride and 3(methylthio)propionic acid using potassium carbonate and tetrabutylammonium iodide and then co-polymerized with styrene to afford polymer $\mathbf{2 b}$. This polymer was then oxidized with $t$-BHP to afford $\mathbf{3} \mathbf{b}$. The loading level of $\mathbf{3} \mathbf{b}$ was determined by elemental analysis (S content) to be 0.94 $\mathrm{mmol} / \mathrm{g}$. Again, this was in agreement to the loading of $\mathbf{2} \mathbf{b}$ determined by ${ }^{1} \mathrm{H}$ NMR analysis (see experimental). Polymer $\mathbf{3 b}$ was used to oxidize the same set of alcohols that were oxidized with 3a. As can be seen in Table 1, the two polymers afforded comparable yields of ketones. However, removing the sulfoxide moieties from the polymer backbone had no effect and $\mathbf{3 b}$ also failed to work with $\mathbf{4}$ in a multipolymer reaction system.

The study the failure of $\mathbf{4}$ we prepared small molecule analog 5 (Figure 1). The successful application of 5 with polymers $3 \mathbf{a}$ and $\mathbf{3 b}$ in the oxidation 1-(4bromophenyl)ethanol (53\% and $40 \%$ yield, respectively) indicates that the polymeric nature of $\mathbf{4}$ is responsible for failure of the multi-polymer system. Further substantiation of this was found when $\mathbf{4}$ failed to afford the desired product when methyl sulfoxide was activated with oxalyl chloride. All attempts to use $\mathbf{4}$ resulted in intractable polymer residues that were difficult to separate from the reaction mixtures and analysis of the reaction mixtures by thin layer chromatography indicated that no desired product was present. To determine if it is the soluble nature of $\mathbf{4}$ that is the problem, we then examined commercially available insoluble diethylaminomethyl-polystyrene $\operatorname{resin}^{28}$ and Amberlite $^{\circledR}$ IRA-67 ion-exchange resin (basic form) as the base in the multi-polymer system, but they too failed to produce the desired products. 
Table 1. Swern oxidation reactions using polymers $\mathbf{3 a}$ and $\mathbf{3 b .}$

Entry Polymer 3a

We next examined the recycling of the polymers recovered from the oxidation reactions. The mixtures of sulfide and sulfoxide polymers (2a with $\mathbf{3 a}$, and $\mathbf{2} \mathbf{b}$ with $\mathbf{3 b}$ ) recovered from the oxidation reactions were reoxidized using $t$-BHP and the resulting polymers were reused. This cycle was repeated 3 times for both $\mathbf{3 a}$ and $\mathbf{3} \mathbf{b}$ and the results are listed in Table 2 and Table 3, respectively. As can be seen from these tables, the recycled polymers were essentially as effective as were the original polymer with only a modest decrease in yields between cycles. It should be noted that even though reduced yields were observed, the products were all essentially pure after isolation. Although we can not explain the decreased yields, we can say that based on ${ }^{1} \mathrm{H}$ NMR, 3a and $\mathbf{3 b}$ were essentially pure, with all of the sulfur moieties in the sulfoxide oxidation state. ${ }^{29}$ Therefore, incomplete oxidation or over oxidation is not the cause of the observed results. Since the goal of modern combinatorial/parallel synthesis in the context of medicinal chemistry and drug discovery is the direct rapid production of pure compound samples for biological screening, the diminishing performance of $\mathbf{3 a}$ and $\mathbf{3 b}$ upon recycling may not limit their utility.

Interestingly, the fact that these polymers remain soluble and can be recycled at all indicates that previous speculation that the use of oxallyl chloride with polystyrene results in polymer cross-linking is not valid. ${ }^{10}$ If this were to happen, cross-linking of polymers $\mathbf{3} \mathbf{a}$ and $\mathbf{3} \mathbf{b}$ would have made them become insoluble and forced them to precipitate from the reaction mixtures. Therefore, our findings confirm that poor polymer compatibility with water was probably the cause for the previously reported diminished yields upon recycling of related insoluble polymer based sulfoxide reagents and that the use of oxidizing reagents that require organic solvents, such as $t$-BHP, are preferred for polymer reoxidation. $^{27}$

Table 2. Yield of 4'-bromoacetophenone from 1-(4bromophenyl)ethanol oxidation using recycled polymer $3 \mathbf{a}$.

\begin{tabular}{cc}
\hline Cycle Number & Yield (\%) \\
\hline 1 & 92 \\
2 & 86 \\
3 & 79 \\
4 & 75
\end{tabular}

Table 3. Yield of benzil from benzoin oxidation using recycled polymer $\mathbf{3 b}$.

\begin{tabular}{cc}
\hline Cycle Number & Yield (\%) \\
\hline 1 & 80 \\
2 & 70 \\
3 & 63 \\
4 & 59
\end{tabular}

\section{Conclusions}

In summary, two easily prepared and recyclable NCPSbased sulfoxide polymers have been developed that can be used in place of DMSO in Swern oxidation reactions. In the oxidation of secondary alcohols, the polymers afforded 
comparable yields of ketones that were isolated in essentially pure form via two simple filtration operations. The polymers were removed from the reaction product and recovered for reuse by precipitation and filtration. Oxidation of both the initially prepared and recovered polymers was accomplished using $t$-BHP in the presence of acid. Unfortunately these polymers could not be successfully applied in a multi-polymer oxidation system. Considering the ease of preparation, cost of the starting materials, and chemical stability, polymer $\mathbf{3 a}$ is preferred to 3b. Since reagent recycling is not a major issue in modern drug discovery, the observed diminishing yields upon reuse of the polymers is not detrimental and 3a should be useful in medicinal chemistry for the rapid synthesis of pure compounds for biological screening. The use of polymer 3a in the high-throughput parallel synthesis of compounds that can be isolated essentially pure is currently being investigated.

\section{Experimental}

\subsection{General}

All reagents were obtained from the Aldrich Chemical companies or TCI Tokyo Kasei Organic Chemicals and were used without further purification. All moisture sensitive reactions were carried out in dried glassware under a nitrogen atmosphere. Tetrahydrofuran was distilled under a nitrogen atmosphere over sodium and benzophenone. Dichloromethane and dimethyl formamide were distilled from calcium hydride. Merck silica gel 60 (230-400 mesh) was used for chromatography and filtration. Thin layer chromatography analysis was performed using glass plates coated with silica gel $60 \mathrm{~F}_{254}$. The NMR spectra were recorded using a Bruker DRX 400 spectrometer. Chemical shift data is expressed in ppm with reference to TMS. Elemental analyses were conducted at the Analytical and Testing Center of the Shanghai Institute of Organic Chemistry.

4.2. 4-Vinylphenyl methyl sulfide (1a). ${ }^{26}$ Methyl disulfide (21.6 g, $229 \mathrm{mmol}$ ) was added slowly at $0{ }^{\circ} \mathrm{C}$ to a solution of the Grignard reagent prepared from 4-bromostyrene (28.0 g, $153 \mathrm{mmol})$ and $\mathrm{Mg}$ (7.4 g, $305 \mathrm{mmol})$ in dry THF (200 mL). The mixture was stirred at room temperature for $3 \mathrm{~h}$. At this time, the reaction mixture was diluted with diethyl ether (500 $\mathrm{mL})$, and then washed sequentially with water (250 $\mathrm{mL}), 10 \%$ aqueous $\mathrm{HCl}(250 \mathrm{~mL})$, saturated aqueous $\mathrm{NaHCO}_{3}(250 \mathrm{~mL})$ and brine $(250 \mathrm{~mL})$. The organic layer was dried over $\mathrm{MgSO}_{4}$, filtered and concentrated in vacuo. The crude product was purified by silica gel chromatography (5\% EtOAc/hexanes) to afford 1a as a clear, colorless liquid (16.0 g, 70\%). ${ }^{1} \mathrm{H}$ NMR (400 MHz, $\mathrm{CDCl}_{3}$ ) $\delta 2.45$ (s, 3H), 5.21 (dd, $1 \mathrm{H}, J=10.9,0.9 \mathrm{~Hz}$ ), 5.70 (dd, $1 \mathrm{H}$, $J=17.6,0.9 \mathrm{~Hz}$ ), 6.68 (dd, $1 \mathrm{H}, J=17.6,10.9 \mathrm{~Hz}), 7.17-$ 7.40 (m, 4H). ${ }^{13} \mathrm{C}$ NMR (100 MHz, $\mathrm{CDCl}_{3}$ ) $\delta$ 15.7, 113.1, 126.6 (4C), 134.5, 136.2, 138.0. HR FAB-MS: calcd for $\mathrm{C}_{9} \mathrm{H}_{10} \mathrm{~S}, 150.0503$; found, 150.0500 .
4.3. 4-Vinylbenzyl 3-(methylthio)propanoate (1b). To an anhydrous DMF (200 mL) solution of 4-vinylbenzylchloride (21.7 g, $140 \mathrm{mmol}$ ) was added 3-(methylthio)propionic acid (19.0 mL, $170 \mathrm{mmol}$ ), potassium carbonate (38.7 g, 280 mmol) and tetrabutylammonium iodide (5.2 g, $14 \mathrm{mmol})$. The reaction mixture was stirred for $24 \mathrm{~h}$ at $50{ }^{\circ} \mathrm{C}$. After cooling to room temperature it was then filtered through Celite and concentrated in vacuo. The crude product was dissolved in $\mathrm{CH}_{2} \mathrm{Cl}_{2}$ (300 mL) and washed sequentially with $10 \%$ aqueous $\mathrm{HCl}(250 \mathrm{~mL})$, saturated, aqueous $\mathrm{NaHCO}_{3}$ $(250 \mathrm{~mL})$ and brine $(250 \mathrm{~mL})$. The organic layer was dried over $\mathrm{MgSO}_{4}$, filtered, and concentrated in vacuo. The crude product was purified by silica gel chromatography (5\% EtOAc/hexanes) to afford $\mathbf{1 b}$ as a pale yellow liquid (20.6 g, 62\%). $\left.{ }^{1} \mathrm{H} \mathrm{NMR} \mathrm{(400} \mathrm{MHz,} \mathrm{CDCl}_{3}\right) \delta 2.11$ (s, 3H), 2.67 (t, 2H, $J=7 \mathrm{~Hz}$ ), 2.76 (t, 2H, J = $7 \mathrm{~Hz}$ ), 5.13 (s, 2H), 5.26 (dd, $1 \mathrm{H}, J=10.9,0.8 \mathrm{~Hz}$ ), 5.76 (dd, $1 \mathrm{H}, J=17.6,0.8 \mathrm{~Hz}$ ), 6.72 (dd, $1 \mathrm{H}, J=17.6,10.9 \mathrm{~Hz}), 7.25-7.47$ (m, 4H). ${ }^{13} \mathrm{C}$ NMR $\left(400 \mathrm{MHz}, \mathrm{CDCl}_{3}\right) \delta 15.5,29.1,34.5,66.3,114.4,126.4$, 128.5, 135.2 (2C), 136.3, 137.7 (2C), 171.8. HR FAB-MS: calcd for $\mathrm{C}_{13} \mathrm{H}_{16} \mathrm{O}_{2} \mathrm{~S}$, 236.0871; found, 236.0817.

\subsection{NCPS-sulfide polymers.}

4.4.1. Poly(styrene-co-4-vinylphenyl methyl sulfide) (2a). To a solution of styrene (55.5 g, $533 \mathrm{mmol})$ and 1a (10.0 g, $67 \mathrm{mmol})$ in toluene $(400 \mathrm{~mL})$ was added AIBN (0.4 g, 3 mmol). The mixture was purged with $\mathrm{N}_{2}$ for $30 \mathrm{~min}$ and the solution was stirred at $90^{\circ} \mathrm{C}$ for $24 \mathrm{~h}$. The solution was concentrated in vacuo and then the residue was taken up in $40 \mathrm{~mL}$ of THF. This solution was added dropwise to a vigorously stirred cold methanol ( 1 L). The white precipitate was filtered and dried to afford $2 \mathbf{2 a}$ as a white powder (25.7 g, 36\%). ${ }^{1} \mathrm{H}$ NMR (400 MHz, $\left.\mathrm{CDCl}_{3}\right) \delta 1.26-$ 2.05 (bm, 21H), 2.42 (bs, 3H) and 6.23-7.19 (bm, 33H). The ratio of monomer incorporation into $2 \mathbf{a}$ was determined by ${ }^{1} \mathrm{H}$ NMR to be 6:1 (styrene:1a).

4.4.2. Poly(styrene-co-4-vinylbenzyl 3-[methylthio]propanoate) (2b). To a solution of styrene (35.3 g, $339 \mathrm{mmol}$ ) and $\mathbf{1 b}(10.0 \mathrm{~g}, 42 \mathrm{mmol})$ in toluene $(400 \mathrm{~mL})$ was added AIBN (0.3 g, $2 \mathrm{mmol})$. The mixture was purged with $\mathrm{N}_{2}$ for $30 \mathrm{~min}$ and the solution was stirred at $90^{\circ} \mathrm{C}$ for $24 \mathrm{~h}$. The solution was concentrated in vacuo and then the residue was taken up in $40 \mathrm{~mL}$ of THF. This solution was added dropwise to vigorously stirred cold methanol $(1 \mathrm{~L})$. The white precipitate was filtered and dried to afford $\mathbf{2} \mathbf{b}$ as a white powder (24.0 g, 52\%). ${ }^{1} \mathrm{HNMR}\left(400 \mathrm{MHz}, \mathrm{CDCl}_{3}\right) \delta$ 1.21-2.09 (bm, 24H), 2.11 (bs, 3H), 2.67 (bs, 2H), 2.78 (bs, $2 \mathrm{H}), 5.05$ (bs, $2 \mathrm{H})$ and 6.20-7.21 (bm, 36H). The ratio of monomer incorporation into $\mathbf{2 b}$ was determined by ${ }^{1} \mathrm{H}$ NMR to be 8:1 (styrene:1b).

\subsection{NCPS-sulfoxide polymers.}

4.5.1. Poly(styrene-co-4-vinylphenyl methyl sulfoxide) (3a). A solution of 2 a (25.7 g, $33 \mathrm{mmol})$ in $\mathrm{CH}_{2} \mathrm{Cl}_{2}(200$ $\mathrm{mL})$ was treated with $70 \% \mathrm{t}$-BHP $(21.7 \mathrm{~mL}, 157 \mathrm{mmol})$ and para-toluenesulfonic acid (6.3 g, $33 \mathrm{mmol})$. The mixture was stirred at room temperature for $24 \mathrm{~h}$ and then 
concentrated in vacuo. The residue was taken up in $50 \mathrm{~mL}$ of THF and this solution was added dropwise to a vigorously stirred cold methanol (1 L). The white precipitate was filtered and dried to afford $3 \mathbf{3}$ as a white powder (24.9 g, 94\%). A sulfur loading level of 1.25 $\mathrm{mmol} / \mathrm{g}$ was determined by elemental analysis. ${ }^{1} \mathrm{H}$ NMR $\left(400 \mathrm{MHz}, \mathrm{CDCl}_{3}\right) \delta$ 1.26-2.05 (bm, 21H), 2.62 (bs, 3H) and 6.23-7.19 (bm, 33H). The ratio of monomer incorporation into 3a was determined by elemental analysis $(4.03 \% \mathrm{~S})$ to be 6.1:1 (styrene:1a). This corresponds to a loading level of $1.25 \mathrm{mmol} / \mathrm{g}$ of polymer.

4.5.2. Poly(styrene-co-4-vinylbenzyl 3-[methylsulfinyl] propanoate) (3b). A solution of $2 \mathbf{b}(24.0 \mathrm{~g}, 22 \mathrm{mmol})$ in $\mathrm{CH}_{2} \mathrm{Cl}_{2}(200 \mathrm{~mL})$ was treated with $70 \% t$-BHP $(13.8 \mathrm{~mL}$, $100 \mathrm{mmol}$ ) and para-toluenesulfonic acid (4.2 g, $22 \mathrm{mmol})$. The mixture was stirred at room temperature for $24 \mathrm{~h}$ and then concentrated in vacuo. The residue was taken up in 50 $\mathrm{mL}$ of THF and this solution was added dropwise to vigorously stirred cold methanol (1 L). The white precipitate was filtered and dried to afford $\mathbf{3 b}$ as a white powder (23.7 g, 95\%). A sulfur loading level of 0.94 $\mathrm{mmol} / \mathrm{g}$ was determined by elemental analysis. ${ }^{1} \mathrm{H}$ NMR $\left(400 \mathrm{MHz}, \mathrm{CDCl}_{3}\right) \delta$ 1.27-2.00 (bm, 24H), 2.55 (bs, 3H), 2.87 (bs, 2H), 3.00 (bs, 2H), 5.05 (bs, 2H) and 6.20-7.21 (bm, $36 \mathrm{H})$. The ratio of monomer incorporation into $\mathbf{3 b}$ was determined by elemental analysis $(3.06 \% \mathrm{~S})$ to be $7.8: 1$ (styrene:1b). This corresponds to a loading level of 0.94 $\mathrm{mmol} / \mathrm{g}$ of polymer.

4.6. General procedure for alcohol oxidation. A solution of $3 \mathbf{a}$ or $\mathbf{3 b}(4 \mathrm{eq})$ in anhydrous $\mathrm{CH}_{2} \mathrm{Cl}_{2}(30 \mathrm{~mL})$ was cooled to $-70{ }^{\circ} \mathrm{C}$ and oxalyl chloride (3.7 eq) was added dropwise. After $30 \mathrm{~min}$ a solution of the alcohol (1 eq) in anhydrous $\mathrm{CH}_{2} \mathrm{Cl}_{2}$ was added. The mixture is stirred for at low temperature for $1 \mathrm{~h}$ and then triethylamine (6 eq) was added. The solution is kept at $-40{ }^{\circ} \mathrm{C}$ for $1 \mathrm{~h}$ and then allowed to warm to room temperature. The reaction mixture was then concentrated in vacuo and then THF (10-15 mL) was added. The solution was then poured into cold methanol $(100 \mathrm{~mL})$ to precipitate the polymer. ${ }^{30}$ After filtration the filtrate is concentrated in vacuo and the crude residue was filtered through a plug of silica gel to provide essentially pure oxidized product. (Table 1). These reactions were typically performed on a 1 millimole scale.

4.7. General procedure for recycling of the sulfoxide polymers $3 \mathbf{a}$ and $\mathbf{3 b}$. The polymer mixtures (2a and $\mathbf{3 a}$ or $\mathbf{2 b}$ and $\mathbf{3 b}$ ) recovered from the oxidation reactions were treated with 70\% $t$-BHP (5 eq) and para-toluenesulfonic acid (1 eq) in $\mathrm{CH}_{2} \mathrm{Cl}_{2}(50 \mathrm{~mL})$. The mixture was stirred at room temperature for $24 \mathrm{~h}$ and then concentrated in vacuo. The residue was taken up in $20 \mathrm{~mL}$ of THF and this solution was added dropwise to vigorously stirred cold methanol $(100 \mathrm{~mL})$. The white precipitate was filtered and dried. The polymers were determined to be completely and cleanly oxidized to either $3 \mathbf{a}$ or $\mathbf{3 b}$ by ${ }^{1} \mathrm{H}$ NMR analysis. ${ }^{31}$
4.8. $N, N$-Diethyl-4-methylbenzylamine (5). ${ }^{32}$ To а THF (100 mL) solution of 4-methylbenzyl chloride (21.2 g, 151 mmol) was added diethylamine (13.5 g, $186 \mathrm{mmol})$ and 30 $\mathrm{mL}$ of $5 \mathrm{~N}$ aqueous $\mathrm{NaOH}$. The reaction mixture was stirred for $24 \mathrm{~h}$ at room temperature. At this time, the reaction mixture was poured into water was extracted with diethyl ether $(4 \times 100 \mathrm{~mL})$. The combined organic layers were dried with $\mathrm{MgSO}_{4}$, filtered, and concentrated in vacuo. The light-yellow crude product was purified by distillation (90 ${ }^{\circ} \mathrm{C}, 0.4 \mathrm{~mm} \mathrm{Hg}$ ) to afford 5 as a clear, colorless liquid (20.9 g, $78 \%$ ). ${ }^{1} \mathrm{H}$ NMR (400 MHz, $\mathrm{CDCl}_{3}$ ) $\delta 1.03$ (t, 6H, $J=7.1$ $\mathrm{Hz}$ ), 2.33 (s, 3H), 2.51 (q, 4H, $J=7.1 \mathrm{~Hz}$ ), 3.52 (s, 2H), 7.11 (d, $2 \mathrm{H}, J=8 \mathrm{~Hz}), 7.21$ (d, $2 \mathrm{H}, J=8 \mathrm{~Hz}) .{ }^{13} \mathrm{C}$ NMR $(100$ $\mathrm{MHz}, \mathrm{CDCl}_{3}$ ) $\delta$ 11.7, 21.0, 46.5, 57.1, 128.7 (2C), 128.8 (2C), 135.9, 136.7. HR FAB-MS: calcd for $\mathrm{C}_{12} \mathrm{H}_{19} \mathrm{~N}$, 177.1517; found, 177.1516 .

\section{Acknowledgments}

This research was supported financially by the University of Hong Kong and the Research Grants Council of the Hong Kong Special Administrative Region, P. R. of China (Project No. HKU 7112/02P). We would also like to thank Mr. Michael McNello and the Aldrich Chemical Company for their gift of many of the reagents used in this project.

\section{References}

1. (a) Mancuso, A. J.; Huang, S. L.; Swern, D. J. Org. Chem. 1978, 43, 2480-2482. (b) Omura, K.; Swern, D. Tetrahedron 1978, 34, 1651-1660. (c) Mancuso, A. J.; Brownfain, D. S.; Swern, D. J. Org. Chem. 1979, 44, 4148-4150. (d) Mancuso, A. J.; Swern, D. Synthesis 1981, 165-185. (e) Marx, M.; Tidwell, T. T. J. Org. Chem. 1984, 48, 788-793. (f) Tidwell, T. T. Org. React. 1990, 39, 297-572. (g) Tidwell, T. T. Synthesis 1990, 857-870.

2. (a) Frigerio, M.; Santagostino, M.; Sputore, S.; Palmisano, G. J. Org. Chem. 1995, 60, 7272-7276. (b) Bisai, A.; Chandrasekhar, M.; Singh, V. K. Tetrahedron Lett. 2002, 43, 8355-8357.

3. Albright, J. D.; Goldman, L. J. Am. Chem. Soc. 1967, 89, 24162423.

4. Albright, J. D. J. Org. Chem. 1974, 39, 1977-1979.

5. Takano, S.; Inomata, K.; Tomita, S.; Yanase, M.; Samizu, K.; Ogasawara, K. Tetrahedron Lett. 1988, 29, 6619-6620.

6. De Luca, L.; Giacomelli, G.; Porcheddu, A. J. Org. Chem. 2001, 66, 7907-7909.

7. (a) Chrisman, W.; Singaram, B. Tetrahedron Lett. 1997, 38, 2053-2056. (b) Estieu, K.; Paugam, R.; Ollivier, J.; Salaun, J.; Cordero, F. M.; Goti, A.; Brandi, A. J. Org. Chem. 1997, 62, 8276-8277. (c) Schmitz, W. D.; Messerschmidt, N. B.; Romo, D. J. Org. Chem. 1998, 63, 2058-2059. 
8. Ley, S. V.; Baxendale, I. R.; Bream, R. N.; Jackson, P. S.; Leach, A. G.; Longbottom, D. A.; Nesi, M.; Scott, J. S.; Storer, R. I.; Taylor, S. J. J. Chem. Soc. Perkin Trans. 1 2000, 3815-4195.

9. For selected applications of various insoluble polymer supported oxidizing reagents that do not involve the activation of a methyl sulfoxide see: (a) Wade, L. G.; Stell, L. M. J. Chem. Ed. 1980, 57, 438. (b) Frechet, J. M. J.; Darling, P.; Farrall, M. J. J. Org. Chem. 1981, 46, 1728-1730. (c) Bergbreiter, D. E.; Chandran, R. J. Am. Chem. Soc. 1985, 107, 4792-4793. (d) Hinzen, B.; Ley, S. V. J. Chem. Soc. Perkin Trans. 1 1997, 1907-1908. (e) Dodd, D. S.; Wallace, O. B. Tetrahedron Lett. 1998, 39, 5701-5704. (f) Ley, S. V.; Bolli, M. H.; Hinzen, B.; Gervois, A. G.; Hall, B. J. J. Chem. Soc. Perkin Trans. 1 1998, 2239-2241. (g) Bhalay, G.; Dunstan, A.; Glen, A. Synlett 2000, 12, 1846-1859.

10. Liu, Y.; Vederas, J. C. J. Org. Chem. 1996, 61, 78567859.

11. In related work, an earlier report described the use of an insoluble methyl phenyl sulfoxide reagent that was activated with chlorine. Crosby, G. A.; Weinshenker, N. M.; Uh, H.-S. J. Am. Chem. Soc. 1975, 97, 2232-2235.

12. Harris, J. M.; Liu, Y.; Chai, S.; Andrews, M. D.; Vederas, J. C. J. Org. Chem. 1998, 63, 2407-2409.

13. (a) Crich, D.; Neelamkavil, S. J. Am. Chem. Soc. 2001, 123, 7449-7450. (b) Crich, D.; Neelamkavil, S. Tetrahedron 2002, 58, 3865-3870.

14. Nishide, K.; Ohsugi, S.; Fudesaka, M.; Kodama, S.; Node, M. Tetrahedron Lett. 2002, 43, 5177-5179.

15. (a) Gravert, D. J.; Janda, K. D. Chem Rev. 1997, 97, 489-509. (b) Toy, P. H.; Janda, K. D. Acc. Chem. Res. 2000, 33, 546-554. (c) Dickerson, T. J.; Reed, N. N.; Janda, K. D. Chem. Rev. 2002, 102, 3325-3344. (d) Bergbreiter, D. E. Chem. Rev. 2002, 102, 3345-3384.

16. Shemyakin, M. M.; Ovchinnikov, Y. A.; Kinyushkin, A. A.; Kozhevnikova, I. V. Tetrahedron Lett. 1965, 6, 2323-2327.

17. (a) Chen, S.; Janda, K. D. J. Am. Chem. Soc. 1997, 119, 8742-8745. (b) Chen, S.; Janda, K. D. Tetrahedron Lett. 1998, 39, 39433946. (c) Lee, K. J.; Angulo, A.; Ghazal, P.; Janda, K. D. Org. Lett. 1999, 1, 1859-1862. (d) Manzotti, R.; Tang, S. Y.; Janda, K. D. Tetrahedron 2000, 56, 7885-7892. (e) Lopez-Pelegrin, J. A.; Janda, K. D. Chem. Eur. J. 2000, 6, 1917-1922.

18. (a) Enholm, E. J.; Gallagher, M. E.; Moran, K. M.; Lombardi, J. S.; Schulte II, J. P. Org. Lett. 1999, 1, 689691. (b) Enholm, E. J.; Schulte II, J. P. Org. Lett. 1999, 1, 1275-1277.

19. (a) Harrison, C. R.; Hodge, P.; Hunt, B. J.; Khoshdel, E.; Richardson, G. J. Org. Chem. 1983, 48, 3721-3728. (b)
Charette, A. B.; Boezio, A. A.; James, M. K. Org. Lett. 2000, 2, 3777-3779. (c) Charette, A. B.; James, M. K.; Boezio, A. A. J. Org. Chem. 2001, 66, 2178-2180.

20. Malagu, K.; Guérin, P.; Guillemin J. C. Synlett 2002, 2, 316-318.

21. Reed, N. N.; Delgado, M.; Hereford, K.; Clapham, B.; Janda, K. D. Bioorg. Med. Chem. Lett. 2002, 12, 20472049.

22. For insoluble polymer bound IBX reagents see: (a) Mülbaier, M.; Giannis, A. Angew. Chem. Int. Ed. 2001, 40, 4393-4394. (b) Sorg, G.; Mengei, A.; Jung, G.; Rademann, J. Angew. Chem. Int. Ed. 2001, 40, 43954397.

23. Toy, P. H.; Reger, T. S.; Janda, K. D. Org. Lett. 2000, 2, 2205-2207.

24. For multipolymer solid-phase peptide synthesis see: (a) Frank, H.; Hagenmaier, H. Experientia 1975, 31, 131133. (b) Heusel, G.; Bovermann, G.; Gohring, W.; Jung, G. Angew. Chem. Int. Ed. 1977, 16, 642-643.

25. For a multipolymer solid-phase Sharpless asymmetric dihydroxylation reaction see: Han, H.; Janda, K. D. Angew. Chem. Int. Ed. 1997, 36, 1731-1733.

26. Hirao, A.; Shione, H.; Ishizone, T.; Nakahama, S. Macromolecules 1997, 30, 3728-3731.

27. Cole, D. C.; Stock, J. R.; Kappel, J. A. Bioorg. Med. Chem. Lett. 2002, 12, 1791-1793

28. Aldrich catalog item 53,733-0.

29. The completeness of the oxidation was monitored by ${ }^{1} \mathrm{H}$ NMR analysis using the S-Me group as the signal of reference.

30. A reviewer raised the issue that methanol may potentially be oxidized to undesirable formaldehyde during this step. There are several simple means to avoid this issue. One is to use hexanes as the precipitation solvent. When it was used to remove both 3a and $\mathbf{3} \mathbf{b}$ from the oxidation of 1-(4bromophenyl)ethanol, $85 \%$ and $70 \%$ yields of $4-$ bromoacetophenone were observed respectively.

31. A reviewer questioned if the use of excess $t$-BHP would lead to sulfone formation. As a test, thioanisole was allowed to react with 20 eq. of $t$-BHP in the presence of $\mathrm{AcOH}$ at rt for 2 days. The only product observed was the sulfoxide. Our findings are in agreement with those reported in reference 27.

32. Oae, S.; Yamada, N.; Fujimori, K.; Kikuchi, O. Bull. Chem. Soc. Jpn. 1983, 56, 248-256 